\title{
Landscape Projects, a Necessity for Hydraulic Works. The Case of Mornos Dam Landscape
}

\author{
M. Ananiadou-Tzimopoulou ${ }^{1} \cdot$ M. $\operatorname{Nana}^{1}$
}

Received: 30 January 2015 / Accepted: 22 July 2015 / Published online: 1 August 2015

(C) Springer International Publishing Switzerland 2015

\begin{abstract}
This article refers to landscape anthropogenic hydrological changes and particularly to the installation of hydraulic engineering projects in wetland ecosystems. It attempts to define how landscape architecture contributes in understanding, designing and planning the landscape while installing engineering projects, seeking for a deeper insight into the critical relationships concerning the ecosystem, the perception of the landscape and the socio-economic spatial values. It proposes the necessity for a landscape architecture project that should be considered as a continuing process that proceeds along with the engineering project and the environmental processes. The theoretically supported approach is followed by applied research in a specific hydraulic engineering project: the water supply dam of the Mornos River, in the prefecture of Phocis in central Greece. This project involves an analysis of the landscape, as well as a design and planning proposal which aim at the ecological improvement, the sustainable development of the area, and the enjoyment of the landscape by residents and visitors.
\end{abstract}

Keywords Landscape architecture for hydraulic works · Water supply dam · Artificial lake · Landscape design and planning

\section{Introduction}

In modern societies, it is obvious that large engineering projects improve life quality, but at the same time they are important factors in shaping the landscape that encloses human life, affecting its ecological, social, and cultural functions and its image, perceived as an articulated unity. This landscape shaping is very often coincidental, resulting to defacing the environment and lowering its habitability (McHarg 1992). The aim of this article is to define theoretically and practically the necessity of a landscape architecture project in order to interweave landscape and engineering projects, especially hydraulic works, into an entity. Delineating

\section{Nana}

marianna.s.nana@gmail.com

1 School of Architecture, Faculty of Engineering, Aristotle University of Thessaloniki, 54124 Thessaloniki, Greece 
the articulated system of hydraulic projects landscape, it is attempted to point out the multifunctional and crucial role of water and wetlands. It is also attempted to outline the methodologies of landscape architecture as a process and subsequently to illustrate this process describing the case study of the dam and artificial lake of Mornos River, in the prefecture of Phocis in central Greece.

\subsection{Water Systems Landscape}

Water is a significant landscape component with an extremely important role in the ecosystem. Wetlands are valuable and vulnerable ecosystems, while water management is crucial not only for most human activities (e.g., potable water, agriculture, leisure activities, etc.), but also for the stability of the environment. This is claimed by many different sciences, such as ecology and geology, as well as sociology, psychology and economics. Water has the ability to flow, as well as to carry living organisms, forming linear and dynamic corridors, important for both their ecological and cultural value (Ureña and Ollero 2001). At the same time, water presence is crucial for the maintenance and stability of most ecosystems and thus of mankind itself. As a result, water management should be considered as a critical point of ecosystem sustainability.

Considering water as a valuable landscape element, it is worth mentioning the statement "if there is magic on the planet, it is contained in water" (Starke and Simonds 2013). Its qualities and forms are infinite in terms of variety and in terms of diversity. These various forms captivate the eye, impel human actions and enrich the experience and pleasure of the landscape (Wang et al. 2012; Bulut and Yilmaz 2009). The area of Mornos River, the main object of this paper, is indicative, as small streams, noisy springs, crystal clear rivers and quiet swamps coexist and enhance the landscape. Generally, it could be said that water is the defining image of the landscape and the determining factor of its spatial physiognomy, while, as Terkenli (2001) states "landscapes are the most visible and eloquent expressions of variable and changing human-environment relationships". Rivers, lakes and many other sources of freshwater have been important for human civilization throughout time, while human cities and activities have had historically an important relationship to surface water. Some of these activities are agriculture, commerce, transportation, fishing and many more, in addition to modern projects such as hydroelectricity and industrial water usage. Human leisure and educational activities relating to water systems should also be mentioned. It is obvious that in the greatest part of the world, human activities have shaped not only the rural, urban and industrial, but also the so-called natural or wild landscape (Benson and Roe 2000). Thus, water as a landscape element refers to a variety of socioeconomic activities and consequently to human presence and interaction with the landscape, affecting both its form and function.

\subsection{Wetlands and Hydraulics: the Landscape Architecture Approach}

Hydraulic engineering projects are generally installed in wetland ecosystems and could be thought, in ecological, perceptual and socioeconomic terms, as invasions of the landscape that have continuing effects on the area. Such an engineering project is the dam at Mornos River, which converted the river into a completely different type of wetland, namely an artificial lake. Landscape architecture is necessarily concerned with such projects. It can be interpreted as the science, art and technique that takes into account the complex requirements of society's needs and engineering projects, together with the diverse landscape factors, in order to project the 
best possible result from an ecological, perceptual and socioeconomic perspective (AnaniadouTzimopoulou 2005). Its approach has to be within a universal, dynamic, sensitive and yet insightful process (Makhzoumi and Pungetti 1999).

Wetlands embody a set of interdependent values and functions related to the ecosystem structure and its use by humans. However, the change of a particular aspect brings about other changes as well. This is directly related to the installation of hydraulic projects, which should be constructed by taking into serious consideration the protection of the existing wetland values and also their maintenance or further enhancement. It is worth noting that even the artificial wetlands are invaluable resources and they must all be protected, considering not only the function for which they were created, but also the ability to obtain multiple values related to the new landscape form (Tsiouris et al. 1991). A careful handling, though, is imperative, in order to contribute to the integration and adaptation of this type of wetlands, in terms of ecology and hydrology (Chamoglou et al. 2014) but also in a socio-cultural or even economic development perspective (Corner 1999).

The installation of engineering projects affects not only biocoenoses, but also the sociocultural functions of the local human community and the aesthetics of the landscape (Zhang and Du 2012). These fields should also be considered in projects dealing with impact assessments, environmental improvement and landscape design and planning, since they are all important for the balance of the landscape. Yet, a project is needed that will encompass the consideration of the ecosystem diversity and stability as well as the maintenance or emergence of the landscape exceptional beauty and attractiveness, and the conservation of the sociocultural context. Such a project must also not interfere with the hydraulic main purpose and function. Landscape architecture attempts to balance hydraulics and landscape, primarily through design and planning, restoring, enhancing or developing a new landscape. According to this perspective man intervention would take into account the capabilities of the landscape and ensure the balanced coexistence of the engineering project and the ecosystem with the residents or visitors.

\section{Landscape Architecture Projects: a Continuous Process}

From a theoretical perspective, a landscape architecture project should be considered as a process (Morabito 2013), that includes an ongoing analysis of structures and elements, relationships and interactions, all of which result in the creation of design and planning proposals. This analysis includes the studying of the structure and function of the landscape to identify opportunities and potential uses by determining the landscape capacity and suitability for human interventions (Ananiadou-Tzimopoulou 1999), while proposals attempt to encompass and enhance all the ecological, social, cultural and perceptional values of the landscape.

\subsection{Landscape Analysis}

Practically, landscape analysis should always include ecological, sociological and perceptual comprehension of the area. The landscape, as we perceive it, is the image of the area that reflects all the factors that contribute to its current form. Analysis is a precondition for landscape design proposals, and is also a part of the landscape architecture design, or even of any kind of design related to the landscape (Ananiadou-Tzimopoulou 1999). Bibliographic 
resources, maps and aerial photographs, combined with field survey, photographic recording and observation, are the main tools of landscape analysis. Additionally, the primary composition of the data and the systematic recording on maps, plans and diagrams are important stages in analysis. With this perspective, a better understanding of the landscape is achieved, in order to outline its development tendencies, as well as an inspiration or guide for design. This ensures that human intervention does not fight against the forces of nature, but rather works along with them.

\subsection{Design and Planning Proposal}

Landscape architecture contribution is important for all the successive stages of constructing hydraulics: design and installation, as well as short- and long-term use. As a process, landscape design should precede the construction of a project, providing its integration in the landscape, in harmonization with both the natural environment and the socioeconomic structures. Yet the landscape architecture role continues along with the construction and is adjusted during use and over time. Contribution of landscape architecture, either in interdisciplinary cooperation or independently, is important in order to avoid omissions or failures that could be detrimental to ecosystems, socioeconomic factors, and to the project itself. At the same time, landscape design not only reduces the negative impacts, but also gives the surrounding area new social and natural dynamics and perspectives (Karakinari 2005; Nana 2013; Terkenli 2001; Zhang and Du 2012). In other words, hydraulics, while serving their main purpose, could simultaneously upgrade the landscape and offer an overall development of the region. Some research studies on the Greek environment are related to usage and sustainable management of artificial lakes (Chamoglou et al. 2014; Katsoulis 2011; Sargentis and Christoforidis 2002; Skordas and Anagnostopoulou 1995), while a remarkable applied landscape architecture project is the Agia Varvara dam (Ananiadou-Tzimopoulou 2005, 2013) on the Aliakmon River in northern Greece (for DEI-Public Power Corporation SA).

\section{The Mornos Artificial Lake Landscape Architecture Project}

\subsection{General Data of the Project}

Dams are hydraulic engineering projects that affect and transform the landscape. Among them, the artificial lake and the water supply dam of the Mornos River in the prefecture of Phocis in Central Greece was constructed and operated by the Athens Water Supply and Sewerage Company (EYDAP S.A.). A landscape case study was presented by Ananiadou-Tzimopoulou and Nana (2014).

The dam was completed in 1979. It is an earthfill dam with a central core, $139 \mathrm{~m} \mathrm{high,} \mathrm{with}$ a crest length of $815 \mathrm{~m}$ and a crest width of $10 \mathrm{~m}$, that creates an artificial lake of about $14 \mathrm{~km}^{2}$ area, $50 \mathrm{~km}$ perimeter and $770 \times 10^{6} \mathrm{~m}^{2}$ capacity. The lake catchment is about $600 \times 10^{6} \mathrm{~m}^{2}$, consisting of Mornos river, Kokkinos river and Belesitsa stream and supplemented through a conduit from the Evinos reservoir. An aqueduct leads the water to Athens while a small quantity of water is left to flow downstream of the dam. The landscape project covers an area of about $150 \times 10^{6} \mathrm{~m}^{2}$, which is approximately the region perceived as the lake landscape, in other words the south part of the lake catchment area. 


\subsection{Landscape Analysis}

The first part of the project is a socioeconomic, ecological and perceptual analysis of the area, aiming to determine the landscape potential capacity, leading to appropriate landscape proposals. Understanding and documenting the current situation involves data collection on the ecological structure of the area, its history, and the construction and usage of the dam, along with the ecological, social and aesthetic changes that followed the construction. Given the complexity and the scale of the project, the bibliographic research, field survey, and contact with local communities and the dam owner was a long-lasting process. Thus, a more comprehensive and effective landscape approach has been achieved and conclusions have been drawn about the possibilities and prospects of the site potential. Several studies referring to the area contributed specific scientific data (Chatzitheocharous and Ksantakis 2011; Karymbalis et al. 2007; Makropoulos et al. 2010; Sotiropoulos et al. 1991). The conclusions of the landscape analysis were recorded in primarily created maps and plans (Nana 2013), such as the perceptual (Fig. 1), ecological and land use maps. They give information at different levels, such as geographical and socioeconomic data (Fig. 2), visual perception (Fig. 3), and others.

Through the synthetic process of landscape analysis, the physiognomy of the landscape was recorded and comprehended. The Mornos Lake lies amidst the economic centers of Athens, Patras and Lamia and the road network of western Greece (Fig. 2). This centric position is a great advantage of the site. The landscape of Mornos Lake could be characterized as a

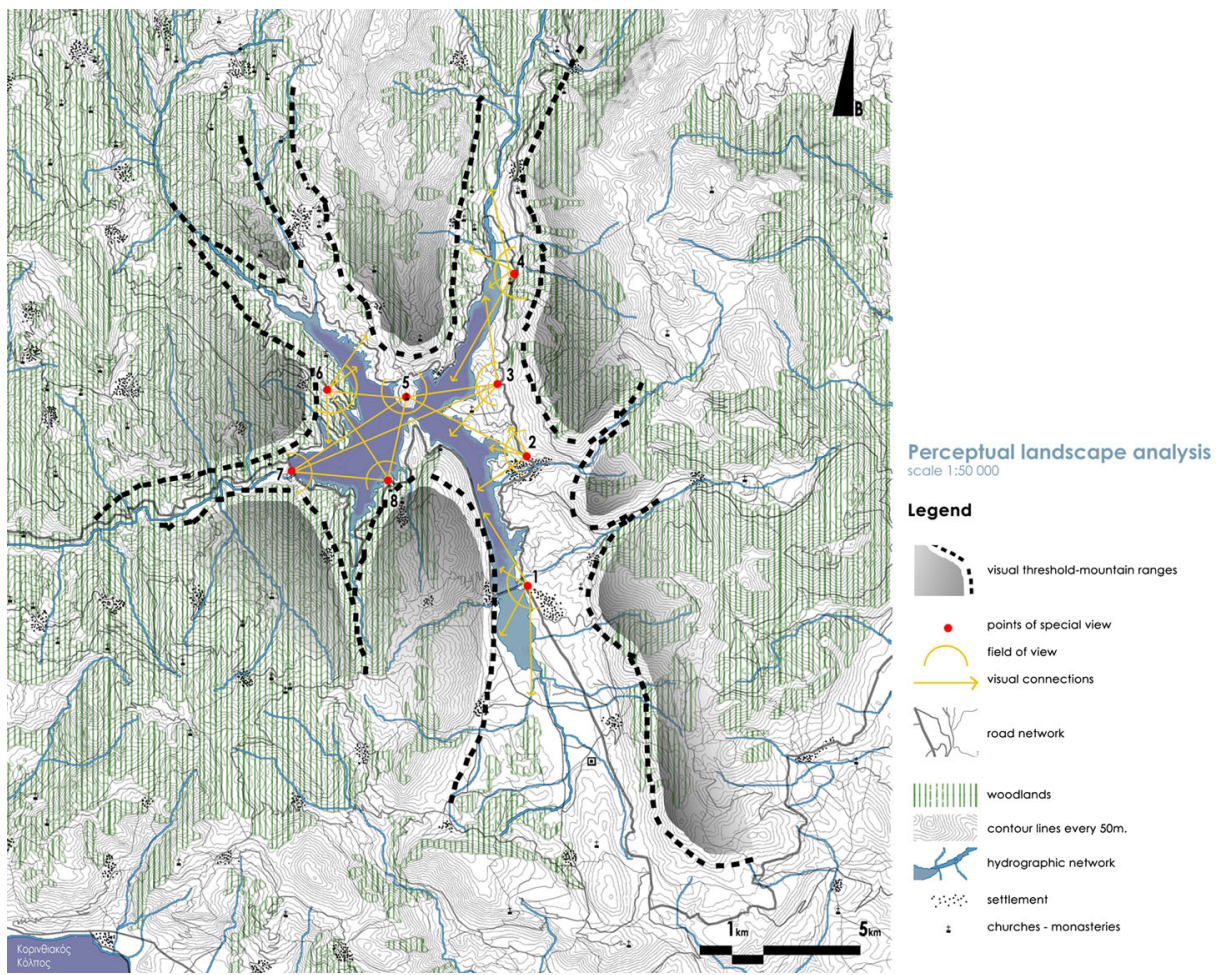

Fig. 1 Perceptual landscape analysis (Nana 2013) 


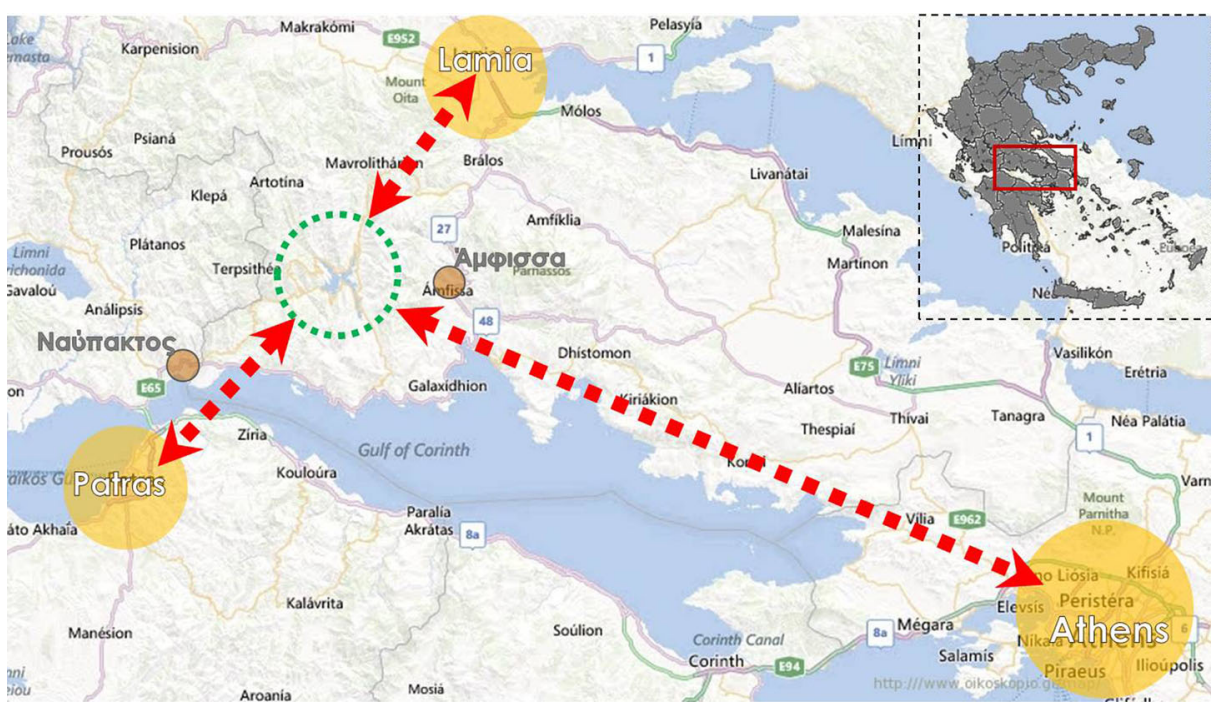

Fig. 2 Mornos Lake correlation to major urban areas (Nana 2013)

Mediterranean mountainous one, particularly rich in biotic and abiotic components. Traces of ancient societies and recent history are an integral part of this area, where a human presence of many centuries is imprinted. On the east side of the area, the presence of people is more clearly evident as there are grasslands, some agricultural fields, and three settlements by the lake. Furthermore, the Mediterranean maquis thrives on this side of the landscape - an indication of human presence over a long period of time. On the contrary, the west side is dominated by forested slopes down to the lake shore. Oak and broadleaf forests are prevalent on this side. The remnants of the ancient castle of Kallipolis on a hilltop almost at the center of the lake could be characterized as the meeting point of these two distinguished sites. This point was the confluence of three rivers before the dam construction. Today these three rivers form the three main arms of the lake which has an amoeboid shape. The dam construction changed the water regime of the wider area, transforming the image and function of the landscape. A variable water level and the conversion of running water into a lake are the main changes in the area.

The lake landscape is enclosed by high mountains, which are the visual boundary of the area, offering impressive view where the steep slopes meet the horizontal surface of the lake. The highest mountains, Giona $(2510 \mathrm{~m})$ and Vardoussia $(2495 \mathrm{~m})$, are in the northeast, while the lower Lidoriki Mountains (1065 m) are in the southwest (Fig. 4). The combination of the

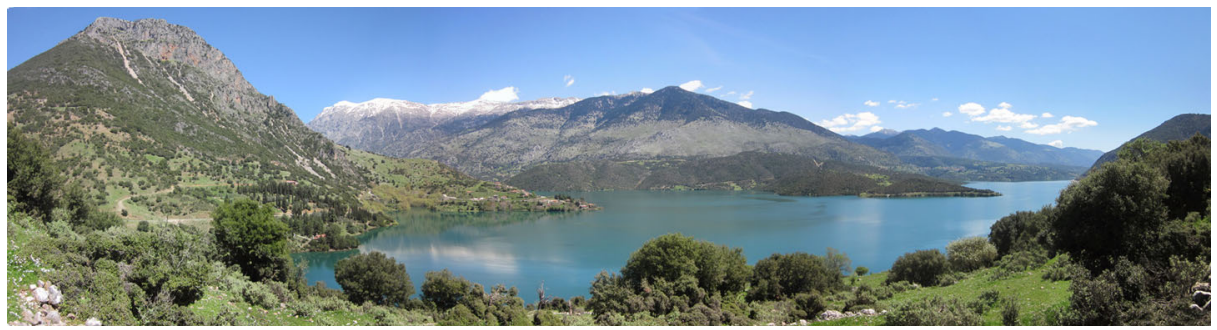

Fig. 3 Lake view from the ancient castle (Nana 2013) 


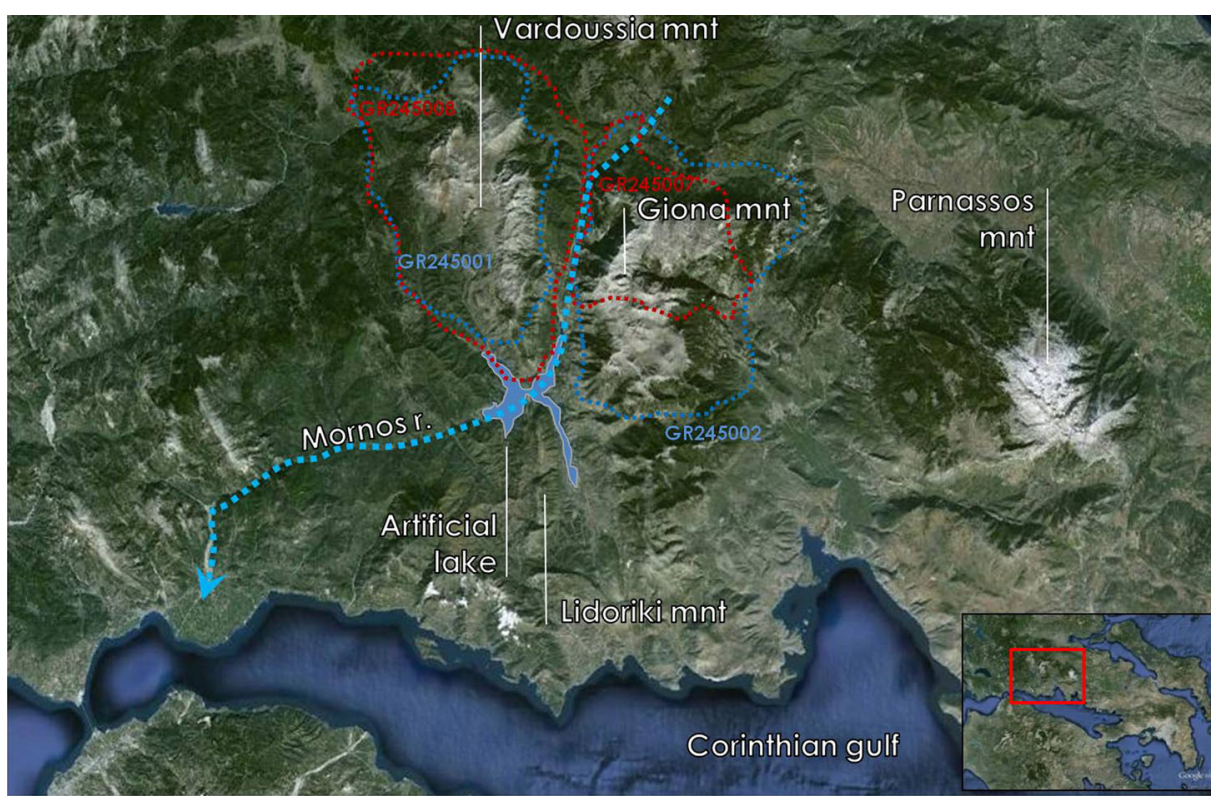

Fig. 4 Wider region geographic elements and Natura 2000 protected areas (Nana 2013)

indented coastline and the impressive high mountains creates four distinct areas which have almost no visual contact among themselves. The scenery of the lake is described by most residents, bystanders and workers at the dam as a landscape of outstanding beauty.

With a view towards the preservation of its natural characteristics, this outstanding landscape has been repeatedly included in international statements as well as in legislation from the Greek state. At the northeast part are four NATURA 2000 sites: two Sites of Community Importance (SCI) - GR2450002 and GR2450001 - and two Special Protection Areas (SPA) - GR2450008, GR2450007 (Fig. 4). There are also two sites of wildlife protection, K348 and K383. Two main characteristics of this area are a great degree of endemism, as well as a widespread presence of most species throughout the area; these result from the rich horizontal and vertical partition and the diversity of habitats found there. More than one hundred important species of flora and fauna, most of them endemic, inhabit the area, while some of the most important species are referred to in Article 4 of Directive 2009/147/EC and listed in Annex II of Directive 92/43/EEC. Such species are birds such as Lullula arborea, Circaetus qallicus, Aquila chrysaetos, Emberiza hortulana, the amphibian Bombina varieqata, mammals such as Lutra lutra, Canis lupus, Rhinolophus mehelyi and Rupicapra rupicapra balcanica and reptiles such as Vipera ursinii. Some important and endemic flora species should also be mentioned such as Arenaria gionae, Aurinia gionae and Astragalus hellenicus (Dafis et al. 1997).

The mountainous topography and the high percentage of forests and protected ecosystems in this region prevents the development of primary sector while at the same time makes the region attractive for tourism. Primary sector tends to decline and it is estimated at around $20 \%$ (NSS 2001). The above peculiarity of the region, combined with the presence of three designated traditional settlements might give an explanation for the shift of the population in the tertiary sector, especially tourism. The production activities of the population of the region tend to concentrate on the rising tertiary sector at $40 \%$ (NSS 2001). 
Concluding, the analysis led to the recognition of four distinguished areas, each one of them having a different character. First, the narrow valley of the Mornos river with fluvial pebble substrate, second the wider valley of the Bellesitsa stream with a silt substrate and dense human presence around it, third the wooded ravines at the east side of the lake and finally the ancient castle on a hill at the center of the lake. As a whole, the area can be described as an impressive lake landscape encircled by high wooded mountains and strewn with indications of human presence. The character of the wetland has changed from a flowing river landscape to a large, mountain-penetrating lake with a small amount of downstream flow. While recognizing the area potential, the new character lead to a landscape design and planning proposal as follows.

\subsection{Landscape Proposal}

\subsubsection{Concept and Objectives}

The landscape architecture proposal for the wider area of the Mornos artificial lake aims to upgrade the landscape by taking advantage of the spatial dynamics and protecting the environment. This multifunctional and visually pleasing landscape appeals to different groups of people and offers a variety of activities, both for residents and visitors of the area. The principles of the proposal are based upon respect of the natural landscape and local communities, as well as of the operating limitations imposed by the dam owner EYDAP.

The place is perceived as a vivid eco-park, its main purpose being to highlight both the natural and the anthropogenic landscape, as well as to improve the residents' life quality and preserve the sustainability of the engineering project and of the surrounding environment. This could be made possible through cooperation of EYDAP with local communities and the forestry agency of that area.

\subsubsection{Economy and Life Quality}

Regarding the social integration of the project, the main objective is that the proposed interventions have lasting value and follow the principles of sustainable development, both in terms of self-sustaining and self-developing structure, and also in terms of sustainable resource management. On a practical level, taking into account the trends of development in the region, the proposal design enables the renewal and improvement of the declining primary production sector and the developing tertiary sector, respectively. The conditions for this combinatorial development have been created while proposals improve the residents' quality of life. Proposed activities such as sustainable tourism, agriecotourism and others are planned according to particular contexts and in combination with the rest of the network activities proposed in the region.

In the project, special care is taken to create a network for cars, bicycles and pedestrians including routes, rest areas, and information and observation points - which would allow the enjoyment, understanding and experience and pleasure of the landscape (Fig. 5). Furthermore, the road network of the area is upgraded by proposing a better interconnection of remote areas and their direct connection to the center of the municipality and the lake.

\subsubsection{Natural and Cultural Perspective}

Particular attention is given to the advancement and growth of the significant landscape from an educational and cultural point of view. The opportunity to approach wetland ecosystems is 


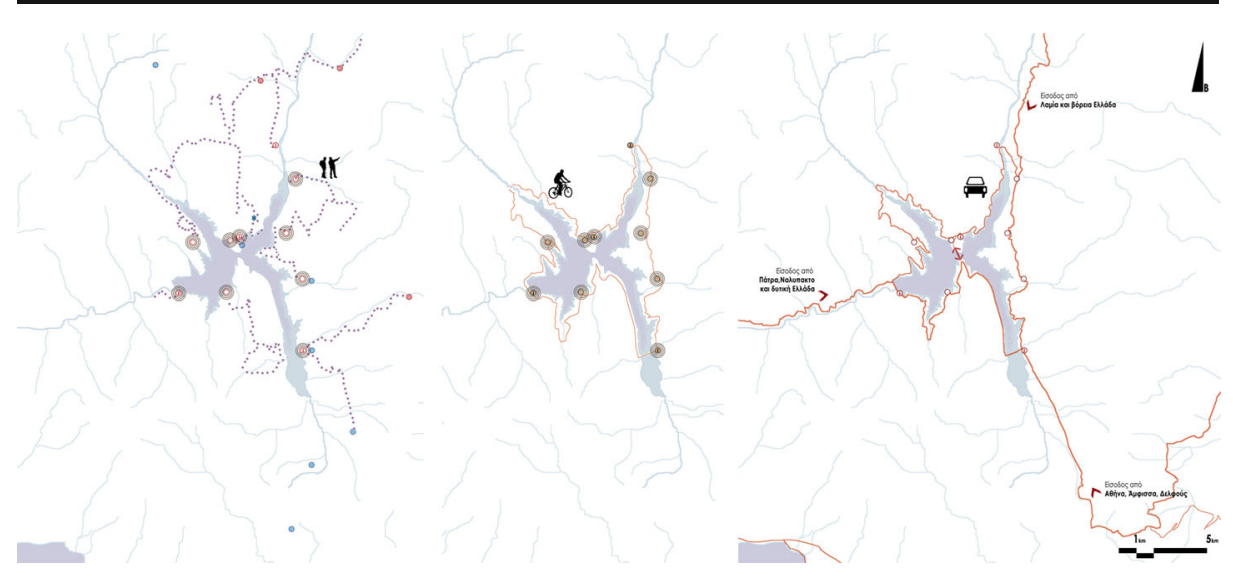

Fig. 5 Diagrammatic proposal layers (Nana 2013)

essential since it provides information and experiences that education within the classroom cannot offer. Furthermore, remnants of past ages are scattered in the landscape, and the understanding of their meaningful presence is more possible by seeing them within the landscape rather than simply reading about them. The landscape proposal makes both natural wealth and cultural heritage legible through appropriate designing solutions in order to be easy for everyone to discover and learn from them. That design also offers the appropriate landmarks and attractions, rest areas and leisure points to eventually appeal to visitors and to give a fresh aspect to residents' daily life. Proposals extend both on the coastal region and the surrounding slopes with mild interventions that do not affect the landscape character. Moreover, contact with the water is proposed through activities that can take place on the lake surface or even underwater, where the visitor can discover the sunken ancient city Kallipoli and the landscape that existed in the area before the construction of the artificial lake (Fig. 6).

\subsubsection{Regional Trademark}

The proposal aims to make use of the new data which the dam construction introduced into the landscape. Dam facilities and its operation are another point of interest for visitors. The landscape is also designed in accordance with the understanding of the dam as an engineering project, which is also a landmark for the region and the main cause of its current form. Thus, the dam could be interpreted as the center of the landscape and the main reason to visit the area.

\section{Conclusion}

The landscape architecture approach is a response to the transformation of the landscape by hydraulic constructions, via thorough ecological, socio-economic and perceptual analysis. The proposal presented is indicative of this approach, aimed to achieve a multifaceted understanding of the landscape and to contribute substantially and positively to its upgrade, restoration and enhancement. This approach is proposed as a necessity for hydraulics in order to achieve a combined sustainable design and planning of the natural and socio-cultural landscape and the engineering project. 


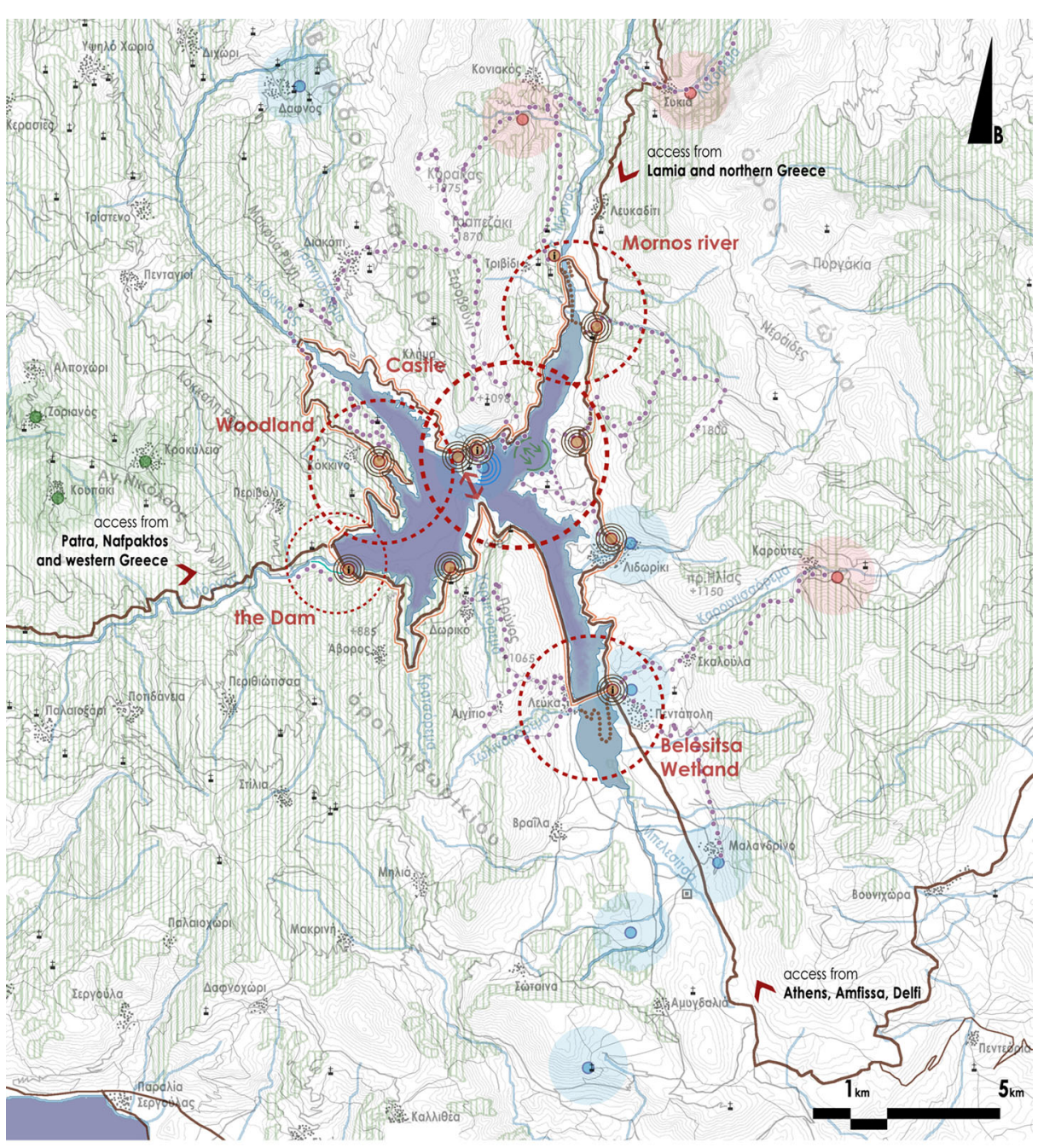

Proposal Master Plan scale 1:50 000

Legend

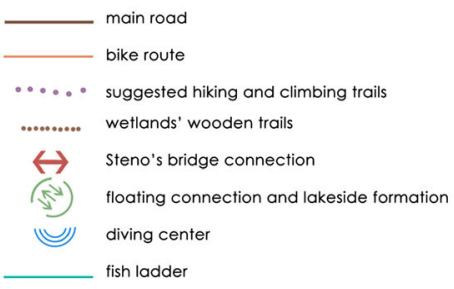

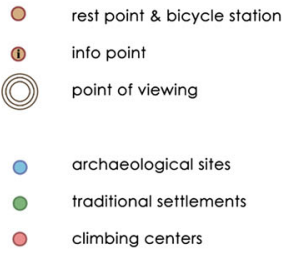

Fig. 6 Landscape Architecture Project / The proposal scale 1:50.000 (Nana 2013)

Through the project proposal, the landscape of the Mornos artificial lake becomes more accessible and eloquent for visitors, being at the same time functional and economically beneficial for residents. It also highlights the cultural, natural and athletic potential of the 
region. The Mornos Lake is no longer merely a reservoir of drinking water for Attica, but a destination with a specific identity and a variety of content.

Acknowledgments An intital version of this work has been presented in the 12th International Conference on Protection and Restoration of the Environment, Skiathos Island, Greece, June 29 to July 3, 2014.

\section{References}

Ananiadou-Tzimopoulou M (1999) Greece: the legacy in landscape design. Topos: State Eur Landsc Archit Munchen 27:88-94

Ananiadou-Tzimopoulou M (2005) Lanscape projects as society's projects. IASME-Int Assoc Mech EngWSEAS Trans 2(4):562-568

Ananiadou-Tzimopoulou M (2013) Enhancement of wider area of St. Barbara Regulating Dam and Lake of Aliakmonas River. Eclic. http://data.prismanet.gr/e-clic/view.php?id=10. Accesed 16 Oct 2014

Ananiadou-Tzimopoulou M, Nana M (2014) Landscape architecture and hydraulics engineering projects; The case of Mornos dam and artificial lake. Proc, Prot Restor Environ XII:1126-1133

Benson J, Roe M (2000) Landscape and sustainability. Spon Press, London

Bulut Z, Yilmaz H (2009) Determination of waterscape beauties through visual quality assessment method. Environ Monit Assess 154:459-468. doi:10.1007/s10661-008-0412-5

Chamoglou M, Papadimitriou T, Kagalou I (2014) Key-descriptors for the functioning of a Mediterranean reservoir: the case of the New lake Karla-Greece. Environ Process 1:127-135. doi:10.1007/s40710-0140011-0

Chatzitheocharous K, Ksantakis M (2011) Drainages Study and Wastewater Treatment for settlements at Mornos

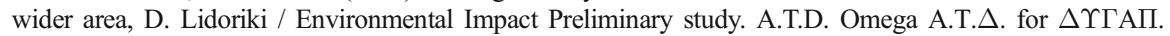
Athens (in Greek)

Corner J (1999) Recovering landscape: essays in contemporary landscape architecture. Princeton Architectural Press, New York

Dafis S, Papstergiadou E, Georgiou K, Babalonas D, Georgiadis Th, et al. (1997) Directive 92/43/EEC. The Greek project: Natura 2000 network. Contract number B4-3200 / 84/756, DG XI Commission of European Communities, The Goulandris Natural History Museum - Greek Biotope/Wetland Centre.

Karakinari E (2005) Wetland Landscapes at Western Coastal Thessaloniki. Protection, Enhancement / Landscape Architecture projects for Delta of Gallikos River, Kalochoriou Lagoon and Dendropotamos torrent. Dissertation, Aristotelion University of Thessaloniki (in Greek)

Karymbalis K, Gaki-Papanastassiou K, Maroukian H (2007) Recent Geomorphic Evolution of the fan of the Mornos River. Natural Processes and Human Impacts. Bulletin of Geological Society of Greece vol. XXXX, 2007. Proceedings of the 11th International Congress, Athens

Katsoulis A (2011) Touristic development of artificial lakes. Dissertation, National Technical University of Athens (in Greek)

Makhzoumi J, Pungetti G (1999) Ecological landscape design and planning: the Mediterranean context. E \& FN Spon, London

Makropoulos F. ed., Damigos D and Benardos A (2010) Assessment of environmental costs and cost proposals, measures and actions to a policy of sustainable development of water resources. Ministry of Infrastructure, Transport and Networks \& NTUA (Department of Water Resources and Environment). Athens. (in Greek)

McHarg IL (1992) Design with nature. Wiley, New York

Morabito V (2013) Landscape process; Tourism of Identity for the Mines of Ingesiente - Sardinia. Aracne, Rome

Nana M (2013) Landscape Architecture and Large Engineering Projects • Hydraulics; The case of the dam and the artificial lake of Mornos. Dissertation, Aristotle University of Thessaloniki (in Greek)

NSS - National Statistical Service (2001) Resident Population Census

Sargentis F and Christoforidis A (2002) Investigation of management and protection possibilities of the quality of Lake Plastiras - part 4: Lake Landscape. Dissertation, National Technical University of Athens (in Greek)

Skordas K and Anagnostopoulou M (1995) Sustainable management of Kerkini's lake water: Serres training program. Greek Biotope \& Wetland Centre, Environmental Planning office. Anima Graphics. Thessaloniki (in Greek)

Sotiropoulos I, Alkalais I and Kavadas M (1991) Mornos Dam, 2nd semi-annual report, issue 1. Geotechnical offices Consortium: Geomechanical EIA for water authority. Athens. (in Greek) 
Starke BW, Simonds JO (2013) Landscape architecture; a manual of environmental planning and design. McGraw-Hill Education, New York

Terkenli T (2001) Towards a theory of the landscape: the Aegean landscape as a cultural image. Landsc Urban Plan 57:197-208. doi:10.1016/S0169-2046(01)00204-3

Tsiouris S, Gerakis D. and Pantazis A (1991) Wetlands of Greece: values, deterioration, protection. AUTH, School of Agriculture, Laboratory of Ecology and Environmental Protection. Thessaloniki (in Greek)

Ureña JM, Ollero A (2001) Fluvial landscapes, catchment administration and land-use planning: experience based on two rivers in Spain. Landsc Res 26:225-243. doi:10.1080/01426390120068918

Wang B, He P, An S, Shen S (2012) Modeling scenic quality of wetland landscape resources in South Dongting Lake, China. Chin Geogr Sci 22:578-589. doi:10.1007/s11769-012-0541-1

Zhang Y, Du M (2012) The approach of landscape architecture to ecological recovery: a case study of the planning and design of the Li lake area. Adv Mater Res 518-523:5954-5958. doi:10.4028/www.scientific. net/AMR.518-523.5954 